\title{
TERMO DE AJUSTAMENTO DE CONDUTA COMO UMA TÉCNICA EXTRAPROCESSUAL PARA A CONCRETIZAÇÃO DO DIREITO AO TRABALHO DECENTE NO SISTEMA CARCERÁRIO DO PARÁ E NO DO AMAZONAS
}

\author{
José Claudio Monteiro de Brito Filho* \\ Juliana Oliveira Eiró do Nascimento**
}

RESUMO: Neste artigo, discute-se o TAC ou ACDH como uma técnica extraprocessual para a concretização do trabalho decente no sistema carcerário do Pará e no do Amazonas. O objetivo é analisar de que maneira o termo pode ser um instrumento para estabelecer os parâmetros para labor decente aos encarcerados no Pará e Amazonas. Por fim, conclui-se que o acordo representaria uma ferramenta adequada para concretizar o trabalho decente aos apenados no Pará e Amazonas, preservando os Direitos Humanos e fundamentais. Na pesquisa, utiliza-se o método hipotético-dedutivo, com uma análise documental e bibliográfica e uma abordagem qualitativa do tema.

PALAVRAS-CHAVE: Trabalho Decente. Trabalho Carcerário. Gestão de Mão de Obra Carcerária no Amazonas-BR. Gestão de Mão de Obra Carcerária no Pará-BR. Termo de Ajustamento de Conduta.

\section{CONDUCT ADJUSTMENT TERM AS AN EXTRAPROCESSUAL TECHNIQUE FOR THE IMPLEMENTATION OF THE RIGHT TO DECENT WORK IN THE CARCERARY SYSTEM OF PARÁ AND AMAZON}

\begin{abstract}
In this article, the TAC or ACDH is discussed as an extra-procedural technique for the realization of decent work in the prison system of Pará and Amazonas. The objective is to analyze how the term can be an instrument to establish the parameters for decent work for prisoners in Pará and Amazonas. Finally, it is concluded that the agreement would represent an adequate tool to achieve decent work for inmates in Pará and Amazonas, preserving human and fundamental rights. In the research, the hypothetical-deductive method is used, with a documental and bibliographic analysis and a qualitative approach to the subject.
\end{abstract}

KEYWORDS: Decent work. Prison work. Management of prison labor in Amazonas-BR. Prison Labor Management in Pará-BR. Conduct adjustment Term.

\section{INTRODUÇÃO}

\footnotetext{
* Doutor em Direito pela PUC/SP. Vice-Coordenador do PPGD/CESUPA. jclaudiobritofilho@ gmail.com. (91) 99144-6580. Endereço: Av. Alcindo Cacela, no 980. Lattes: http://lattes.cnpq.br/7823839335142794. Orcid: https://orcid.org/0000-0002-4435-6450.

Mestranda em Direitos, Políticas Públicas e Desenvolvimento Regional no Centro Universitário do Pará (CESUPA). Integrante do Grupo de Pesquisa em Trabalho Decente (CESUPA/CNPq). Advogada no escritório André Eiró Advogadas. Email: julianaeiro1@ gmail.com. Telefone: (91) 99207-8585. Endereço: Tv. Dom Romualdo de Seixas, 1476, S/ 2508-2509. ID Lattes: 6917896378036887. Orcid: https://orcid.org/0000-00025754-8937.
} 
Conforme dispõe a Declaração Universal dos Direitos Humanos - DUDH -, a dignidade humana é inerente a todos os indivíduos, não sendo possível excepcionar tal direito nem mesmo ao pior indivíduo criminoso condenado. (SARLET, 2016). Além disso, de acordo com a Constituição da República Federativa Brasileira de 1988 (CRFB/88), a dignidade é um dos fundamentos do Estado Democrático de Direito (artigo $1^{\circ}$, III).

Diante dessas premissas garantidoras, Estado passa a ter o dever de se abster de condutas que violem esse valor fundamental, do mesmo modo que deve atuar positivamente para eliminar obstáculos a uma vida digna de todos os sujeitos. (RODRIGUES, 2011)

Em razão disso, o Estado, ao exercer o jus puniendi, deve garantir que, durante o cumprimento da pena, o detento tenha respeitada sua integridade física e mental, bem como, diante das previsões da Lei no 7.210, de 11 de julho de 1984 - Lei de Execuções Penais (LEP) - (BRASIL, 1984), deve criar as condições necessárias para que o criminoso seja ressocializado e retorne ao convívio social. (GRECO, 2015)

Dentre muitos instrumentos ressocializadores, Greco (2015) explica que o trabalho, dentro do cárcere, possui um papel fundamental na (re) integração do encarcerado, tendo em vista a possibilidade de redução dos obstáculos à reinserção no mercado de trabalho do encarcerado, de modo que cria condições para que o sujeito, após o período de privação de liberdade, seja capaz de trabalhar e retornar com autonomia para o convivo social.

Nesse sentido, a LEP, no Capítulo III, determina que o labor dentro do sistema carcerário, como um dever social, deve se dar em condições que respeitem a dignidade humana do encarcerado e que é direito do preso receber a remuneração pela atividade laboral desempenhada. Todavia, poucos parâmetros são estabelecidos para um labor decente.

Dessa forma, tendo em vista que o artigo $28, \S 2^{\circ}$, LEP veda a aplicação da Consolidação das Leis do Trabalho (CLT - Decreto-Lei $n^{\circ}$ 5.452/1943) ao labor penal, temse, atualmente, uma carência legislativa especifica com a finalidade de garantir, dentro do cárcere, a ressocialização penal obrigatória e o direito ao trabalho decente.

Em razão disso, os estados se responsabilizam pela administração do trabalho dos presos, regulamentando a forma com que o labor deve ser desempenhado e os direitos que devem ser assegurados aos encarcerados, além de como deve se dar a relações com as pessoas jurídicas de direito público e privado que se utilizam dessa mão de obra. 
No Amazonas, região de interesse para os fins dessa pesquisa, como consequência, os detentos ficam à mercê de gestões de mão de obra que deixam de assegurar direitos imprescindíveis para um labor decente, gerando a possibilidade de que os encarcerados sejam submetidos as mais precárias formas de labor, que violam Direitos Humanos e fundamentais.

Nesse contexto, uma pesquisa que pretende analisar o uso do Termo de Ajuste de Conduta (TAC) ou Acordo de Concretização de Direitos Humanos (ACDH) como uma técnica extraprocessual para concretizar o trabalho decente no cárcere do Pará e Amazonas, a partir da análise da legislação vigente e da gestão de mão de obra, torna-se imprescindível.

Diante do exposto, a presente pesquisa visará reunir informações com a finalidade de responder ao seguinte problema de pesquisa: De que maneira o TAC ou ACDH pode ser uma técnica extraprocessual usada para concretizar o direito ao trabalho decente aos encarcerados trabalhadores no Pará e Amazonas?

Acredita-se que, sendo o TAC ou ACDH como instrumento extraprocessual capaz de definir prazos e modo concretização de normas constitucionais, políticas públicas e Direitos Humanos, em especial dos direitos sociais e coletivos, além de estipular sansões nas hipóteses de descumprimento do ajuste (SILVA, 2015), a sua utilização representaria uma ferramenta adequada e eficaz para solucionar a problemática causada pela ausência de legislação especifica em prol do trabalho decente dos encarcerados no Pará e Amazonas.

Assim, a pesquisa apresenta relevância pela necessidade de estudos sobre a realidade do labor dentro do cárcere, uma vez que as gestões a que estão submetidos os apenados, não garantem os direitos mínimos necessários ao trabalho decente, constitucionalmente previstos como direitos sociais e compreendidos como Direitos Humanos de segunda dimensão.

Igualmente, verifica-se a imprescindibilidade de se perquirir técnicas processuais e extraprocessuais capazes de preservar a dignidade dos apenados no campo sócio laborativo, afastando qualquer forma de trabalho precário e indigno do sistema carcerário.

Ademais, em vista de garantir a exequibilidade da pesquisa, tornou-se necessário delimitar o campo de análise. Assim, foram selecionados, para exemplificar a gestão de mão da obra encarcerada na região Amazônia, os instrumentos normativos relacionados a administração do labor dos presos no Pará e Amazonas, pois são estados que abrigam uma das 
maior massa carcerária da região, razão pela qual as amostras são suficientemente representativas para atingir os objetivos do presente estudo ${ }^{1}$.

A relevância teórica se dá pela produção de conteúdo que correlacionem a questão trabalhista com o labor nos presídios, possibilitando reflexões sobre a garantia do trabalho decente aos sujeitos presos, bem como o uso do TAC ou ACDH para efetivar o labor digno.

A originalidade da pesquisa se dá pela ausência se literaturas que abordem a aplicação do trabalho decente no sistema carcerário, bem como carência de material bibliográfico que analise meios de solução para a problemática relacionada à ausência de legislação que regulamente o labor em condições que preservem a dignidade dos detentos.

A ausência deste debate é exemplificada pela incipiente produção acadêmica nesta temática. Ao se fazer uma busca no catálogo de Teses e Dissertações da CAPES e na Biblioteca Digital Brasileira de Teses e Dissertações, pelas palavras-chaves "Cárcere e trabalho decente", "Labor digno no sistema carcerário", "Gestão de mão de obra no cárcere", "TAC no sistema carcerário", verificou-se que ainda não se encontram dissertações ou teses que proponham tal análise e investigação. Obtêm-se o mesmo resultado ao inserir as palavraschaves supracitadas no repositório de dissertações do Programa de Pós-Graduação em Direito da Universidade Federal do Pará.

O presente trabalho tem como objetivo geral perquirir de que maneira o TAC ou $\mathrm{ACDH}$ pode ser uma técnica extraprocessual usada para concretizar o direito ao trabalho decente aos encarcerados trabalhadores no Pará e Amazonas.

Para atingir o fim almejado, o presente artigo é estruturado em seis itens, sendo o primeiro esta introdução; o segundo explana sobre a gestão da mão de obra cárcere na região Amazônica; o terceiro analisa o TAC ou ACDH como uma técnica extraprocessual de concretização dos direitos sociais; o quarto de que maneira o TAC ou ACDH poderia ser utilizado para assegurar o trabalho decente dentro do sistema carcerário amazônico. Por fim, o sexto e último item apresenta as considerações finais deste estudo.

O tipo de pesquisa que se apresenta é básica, tendo em vista que se objetiva progresso científico nos ramos do Direito Penal e Trabalhista, no que tange o conhecimento sobre as condições de mão de obra no sistema carcerário amazônico, bem como sobre assuntos pertinentes e relevantes sobre o TAC ou ACDH.

\footnotetext{
${ }^{1}$ Conforme consulta realizada no endereço eletrônico do Ministério da Justiça e Segurança Pública < https://www.gov.br/depen/pt-br/sisdepen/sisdepen>.
} 
No que se refere aos métodos que garantiram as bases lógicas da investigação científica, utiliza-se o hipotético-dedutivo e, ao final, todo o levantamento e análise bibliográfica e documental foi sistematizado de forma qualitativa para fins de conclusão da pesquisa realizada e o trabalho científico será estruturado em forma de artigo cientifico.

Ressalta-se que a pesquisa é exploratória teórica e, quanto aos métodos de procedimento, utiliza-se o bibliográfico, pelo exame pormenorizado de livros e artigos publicados, tendo em vista a necessidade de aprofundar conceitos e fenômenos, além da utilização da dogmática jurídica e legislativa, adequados a pesquisas no ramo do direito.

Quanto às técnicas de pesquisa, utiliza-se a análise de documento de fontes primárias, como normas nacionais e internacionais, princípios constitucionais, bem como secundárias, no que se refere ao exame pormenorizado dos instrumentos que regulamentam o trabalho nos estados do Pará e Amazonas, de livros e artigos publicados na literatura.

\section{GESTÃO DE MÃO DE OBRA CARCERÁRIA NA REGIÃO AMAZÔNICA}

Ao analisar a finalidade da pena imposta ao sujeito criminoso condenado no Brasil, é possível verificar que deve cumprir dupla função: (1) retributiva e (2) preventiva. Desse modo, além de retribuir o mal causado pelo delito ao infrator, a pena deve evitar a ocorrência de outros crimes, por meio, por exemplo, da ressocialização. (GRECO, 2015)

A LEP, em razão disso, impõe ao Estado o dever de atuar positivamente para oportunizar a (re) integração do detento no convívio social (artigo $1^{\circ}$ ). A mesma lei dispõe que o encarcerado tem o direito de receber assistência por parte do Estado para retornar a sociedade, reduzindo assim as chances de reincidência (artigo $10^{\circ}$ ).

Além disso, o mesmo diploma jurídico determina que essa assistência deve ter por finalidade a ressocialização, assegurando, dentro outras coisas, a formação profissional do apenado por meio, por exemplo, do trabalho (artigos 17 a 21). (JULIÃO, 2009).

Diante disso, o labor possui fundamental importância dentro do cárcere, tendo em vista sua capacidade de auxiliar na reintegração do sujeito preso e de reduzir os obstáculos à reinserção no mercado de trabalho, atenuando as discriminações. O trabalho cria condições para que o sujeito seja capaz desempenhar um oficio quando estiver em liberdade e isso permite que o egresso viva com autonomia, evitando a reincidência. (GRECO, 2015) 
Nesse sentido, a LEP determina, no artigo 28, que o trabalho, como um dever social, deve ter por finalidade não somente a produção, mas também, a educação do detento e a sua remuneração, bem como que o labor deve ser praticado em condições que respeitem a noção de dignidade. Além disso, o artigo 38 do Decreto-Lei no 2.848, de 7 de dezembro de 1940 Código Penal (CP) - (BRASIL, 1940) e o artigo $3^{\circ}$ da LEP, assegurarem alguns benefícios que decorrem da prática de atividades laborais, como a progressão de regime e a remição de um dia de pena a cada três dias de labor.

Todavia, apesar de presentes no ordenamento jurídico brasileiro prescrições de que o trabalho no cárcere deve ser desempenhado de forma digna, poucas são as previsões sobre os direitos e garantias a serem assegurados para tanto. Na verdade, o que se observa é que, sobre os direitos sociais devidos aos apenados, apenas há a determinação de que as precauções relativas à segurança e higiene devem ser asseguradas (artigo $28, \S 1^{\circ} \mathrm{LEP}$ ), que a jornada de trabalho dos presos deve seguir o padrão constitucional (artigo 33 LEP) e que o labor deve ser remunerado em um patamar mínimo de 3/4 do salário mínimo vigente (artigo 29 LEP).

Em razão disso, e somado ao fato de a LEP dispor, no artigo $28, \S 2^{\circ}$, que o trabalho carcerário não está acobertado pelo manto de proteção da CLT, constata-se que há uma carência legislativa especifica que tenha por finalidade regulamentar quais os direitos mínimos a serem assegurados aos detentos que laboram no Brasil, bem como que torne o labor carcerário um instrumento efetivo de ressocialização.

Em razão disso, é comum que cada Estados administre a exploração da mão de obra dos encarcerados por meio da elaboração e implementação de instrumentos de gestão que regulam a forma de labor e a maneira de coordenação desse trabalho, além das relações com as pessoas jurídicas de direito público e privado que explorem essa mão de obra. Com isso, torna-se possível que os detentos que laborem tenham diversos direitos, considerados imprescindíveis para que o trabalho se dê em condições dignas, suprimidos.

Tal constatação se confirma, por exemplo, quando se analisa os instrumentos de gestão da mão de obra instituídos nos estados do Pará e no Amazonas, onde se verifica que, apesar de terem avançado um pouco na regulamentação de direitos importantes para o trabalho em condições que preservem a dignidade humana, ainda não são totalmente capazes de garantir condições ótimas de trabalho aos encarcerados, senão vejamos. 
Atualmente, a mão de obra encarcerada no estado do Amazonas é administrada por um projeto de gestão de mão de obra carcerário ${ }^{2}$ formulado pela Secretaria de Administração Penitenciária (SEAP). De acordo com o projeto, o objetivo é promover vagas de trabalho para os presos em regime fechado e semiaberto, contudo, os detentos selecionados para laborar não firmam vínculo empregatício com quem estiver explorando a força de trabalho.

O projeto estabelece que, em síntese, a pessoa sujeita a medida restritiva de liberdade no estado do Amazonas, somente receberá salário mínimo, alimentação, transporte - quando couber -, o valor de $11 \%$ referente ao pagamento da contribuição do regime geral da previdência social (INSS), na qualidade de segurado facultativo, uniforme em quantidade razoável, treinamento e equipamento de proteção Individual - EPI -.

Além disso, a remuneração percebida pelo encarcerado deve atender a seguinte distribuição compensatória: 10\% depositado mensalmente por meio do Documento de Arrecadação (DAR) a título de ressarcimento ao Estado; 5\% destinado ao trabalhador, que será depositado em caderneta de poupança e entregue quando posto em liberdade; $25 \%$ para pagamento de multa se determinada judicialmente; $25 \%$ para assistência familiar e de seus dependentes; e apenas $10 \%$ devido ao trabalhador para custeio de despesas pessoais.

Importa salientar que o projeto do Amazonas determina que aquele que utilize a mão de obra encarcerada tem o dever de adotar medidas que preservem o ambiente de trabalho dos encarcerados nos padrões determinados pelas normas de Segurança e Medicina no Trabalho, assim como devem fornecer todos os materiais, treinamentos e instruções adequadas para uma boa e segura execução da atividade laborativa.

Igualmente, é necessário que realizem o devido controle de jornada de trabalho, que deve respeitar os limites constitucionais, bem como que defina os horários e locais das atividades laborais, efetue o pagamento em dia e emita relatórios sobre as atividades executadas pelos presos para que seja calculada a remissão de pena.

Todavia, o projeto, com base no fundamento legal de que os o labor dos presos não se submete ao regramento da legislação trabalhista, determina expressamente que os trabalhadores não terão direito ao Fundo de Garantia do Tempo de Serviço (FGTS), aviso prévio indenizado ou não, indenização adicional prevista no artigo $9^{\circ}$ da Lei 7.238/84,

\footnotetext{
${ }^{2}$ Atualmente, o Projeto de gestão de mão-de-obra carcerária do estado do Amazonas não está disponível para acesso em nenhuma plataforma digital. Contudo, algumas informações sobre o Projeto podem ser localizadas no site da SEAP-AM, no endereço eletrônico <http://www.seap.am.gov.br/trabalhando-a-liberdade/>.
} 
repouso semanal remunerado, feriados ou dias santificados, férias $+1 / 3$ constitucional, $13^{\circ}$ salário, licença paternidade, contribuição previdenciária.

Além disso, nos casos de acidente de trabalho, o trabalhador preso que contribui para a Previdência Social facultativamente, terá direito ao auxílio-doença, todavia não fara jus ao auxílio-acidente.

Sobre à gestão da mão de obra no Pará, verifica-se que é regulamentada pela Portaria n 465/2020 - GAB/SEAP, editada pelo Secretário de Estado de Administração Penitenciária do Estado do Pará, publicada no Diário Oficial no 34.226, no dia 21 de maio de 2020.

De acordo com a Portaria, o objetivo é normatizar e definir os parâmetros para a realização das atividades laborais do sujeito encarcerado, seja provisório ou sentenciado, custodiado em unidades prisionais do estado ou em unidades hospitalares.

A Portaria dispõe que a jornada de trabalho deve respeita os parâmetros constitucionais, exceto se for cominado um horário especial por conta de algum labor que esteja relacionado com a produção de algum item ou prestação de algum serviço que seja essencial ou emergencial para a SEAP ou de interesse público.

No que se refere à remuneração do sujeito submetido à medida restritiva de liberdade no Pará, será devida apenas uma parcela da bolsa remunerada estabelecida de acordo com a atividade de operações de produção ou de prestação de serviços prestada, senão vejamos.

Nos casos de labor na agropecuária na Colônia Penal Agrícola de Santa Izabel, a bolsa remunerada corresponderá a R \$ 220,00; na Marcenaria na Central de Triagem Metropolitano II e Centro de Recuperação do Coqueiro será de R \$450,00; nos casos de Serviços Gerais em todas as unidades prisionais a bolsa remunerada totalizará R \$ 100,00; no caso do encarcerado realizar Serviços Gerais na sede da SEAP, receberá R\$ 746,77; nas Unidades prisionais produtivas, a bolsa é de $\mathrm{R} \$ 150,00$.

No entanto, se o detento trabalhar para entidades conveniadas, a remuneração deverá estar disposta no instrumento firmado e terá o valor global de 01 (um) salário-mínimo vigente, devendo incluir o percentual da contribuição previdenciária na modalidade de segurado facultativo.

É importante salientar que, a respeito da remuneração liquida percebida por pessoas privadas de liberdade em regime aberto, atenderá a seguinte distribuição compensatória: 25\% da destinado à família e/ou dependente que, na hipótese de inexistência, somará a 
remuneração da pessoa privada de liberdade; $50 \%$ será destinado a pessoa privada de liberdade, para gastos pessoais; bem como $25 \%$ ao ressarcimento do Estado, pelas despesas realizadas com a manutenção da pessoa privada de liberdade.

No caso da remuneração liquida auferida por pessoas privadas de liberdade em regime semi-aberto, a distribuição compensatória se dá de forma diferente, sendo que $25 \%$ poderá ser destinado à família e/ou dependente da pessoa privada de liberdade, 25\% destinado à pessoa privada de liberdade; $25 \%$ à constituição do pecúlio, depositado em conta poupança; bem como $25 \%$ da remuneração ao ressarcimento do Estado.

Salienta-se que o percentual de $25 \%$ destinado aos custos pessoais da pessoa privada de liberdade, apenas poderá ser recebido pelo apenado quando se beneficiar judicialmente licença temporária, progressão de regime, livramento condicional ou alvará de soltura.

No que tange a remuneração daqueles sujeitos em regime fechado, deverá ser distribuída em $25 \%$ à família da pessoa privada de liberdade e/ou dependente que, na hipótese de inexistência, somará ao pecúlio; $50 \%$ à constituição do pecúlio; e $25 \%$ ao ressarcimento do Estado, pelas despesas com a manutenção do custodiado.

Além disso, a Portaria dispõe que, antes de começadas as atividades descritas no convênio de cooperação, o encarcerado deve receber todo o treinamento e direcionamento profissional necessário à adequada execução do serviço.

É importante frisar que, pelo menos em teoria, ambos os instrumentos que tem por finalidade regulamentar a mão de obra encarcerada nesses estados estabelecem determinam que a atividade laboral desempenhada deverá ter finalidade educativa e produtiva, com propósito de capacitação profissional.

Dessa forma, realizado esse panorama geral sobre o trabalho dos encarcerados na região Amazônia, exemplificado pela gestão da mão de obra apenada no Pará e Amazonas, far-se-á uma análise do Termo de Ajustamento de Conduta como um meio extraprocessual de concretização dos direitos sociais.

\section{O TERMO DE AJUSTAMENTO DE CONDUTA COMO UMA TÉCNICA EXTRAPROCESSUAL DE CONCRETIZAÇÃO DOS DIREITOS SOCIAIS}

De acordo com Rodrigues (2011), no Brasil, a CRFB/88 estabeleceu o que se denomina de "cidadania ativa" e definiu alguns instrumentos que permitisse a participação na 
atuação do legislativo, executivo e judiciário. Segundo o autor, a participação na administração ganhou destaque, tendo em vista a multiplicidade e complexidade de funções desempenhadas pelo Executivo.

Nesse cenário, o poder Executivo acabou ficando na frente de todos os outros poderes no que se refere à tomada de decisão e criação de novas regras jurídicas frente a limitação do legislativo em prever todos os cenários possíveis, o que pode gerar entraves para a efetiva e adequada aplicação da norma jurídica. (RODRIGUES, 2011)

Além disso, a autora leciona que o Estado Democrático de Direito Brasileiro consagrou o direito ao acesso à justiça, ou seja, além de garantir os direitos, a CRFB/88, por encontrar fundamento na cidadania e na dignidade da pessoa humana, prescreve uma infinidade de meios para que haja a sua concretização, bem como para que se possam prevenir ou repreender violações de direitos. (RODRIGUES, 2011)

Cabe frisar que, dentre os diversos atores capazes de atuar na concretização desse acesso à justiça, a CRFB/88 estabeleceu que Ministério Público (MP) o dever de zelar pelos interesses do povo, em especial quando violados pelo Poder Público, atribuindo-lhe o poder de usar diversos instrumentos judiciais e extrajudiciais para defesa da ordem democrática e dos direitos humanos de toda coletividade. (RODRIGUES, 2011)

Sobre os mecanismos ofertados pela CRFB/88 para essa atuação do MP, verifica-se que os meios judiciais podem ser, por exemplo, a ação popular, ação civil pública, a ação coletiva, mandado de segurança coletivo e o mandado de injunção coletivo. Além disso, no que se refere aos instrumentos extrajudiciais de concretização, como inquérito civil, recomendação, Instrumentos de promoção de políticas públicas, atividade de mediação, temse o Termo de Ajustamento de Conduta (TAC). (RODRIGUES, 2011)

Frisa-se que Silva (2015) explica que a denominação "TAC" vem sendo substituída por "Acordo de Concretização de Direitos Humanos" (ACDH), e se formaliza pelo "Termo de Acordo de Concretização de Direitos Humanos" (TACDH). Isto porque, o instrumento se tornou um mecanismo de concretização de normas constitucionais, internacionais e políticas públicas que disponham sobre atos, atividades ou normas para garantir Direitos Humanos, em especial os direitos sociais que se relacionam diretamente com os direitos transindividuais.

Essa questão de ligação entre os denominados Direitos Humanos de segunda geração e os direitos transindividuais levantada por Silva (2015) merece ser esclarecida para os fins de 
perquirir a forma como poderia se dá a aplicação do TAC ou ACDH no trabalho no cárcere, como objetiva a presente pesquisa.

De acordo com o artigo $81^{\circ}$ da Lei $\mathrm{n}^{\mathrm{a}}$ 8.078, de 11 de setembro de 1990 - Código de Defesa do Consumidor (CDC) -, os direitos transindividuais são divididos em: (1) difusos, (2) coletivos e (3) individuais homogêneos. De acordo com essa lei, os primeiros seriam de "[...] natureza indivisível, de que sejam titulares pessoas indeterminadas e ligadas por circunstâncias de fato" (artigo 81, I).

Sobre os direitos coletivos, o mesmo instrumento normativo dispõe que correspondem aos direitos "de natureza indivisível de que seja titular grupo, categoria ou classe de pessoas ligadas entre si ou com a parte contrária por uma relação jurídica base” (artigo 81, II), e, sobre os individuais homogêneos, a lei estabelece que são os de origem comum (artigo 81, III).

Para o autor, em virtude das denominações diversas entre direitos econômicos, sociais e culturais, e direitos coletivos, difusos e individuais homogêneos, bem como por estarem previstos em legislações diferentes, muitas vezes esses direitos são tratados como se fosse de naturezas diversas, o que dificulta a proteção dos direitos sociais. Na realidade, segundo o autor, esses direitos estão englobados pela mesma natureza. (SILVA, 2015).

Assim, Silva (2015, p. 84) esclarece que existe uma "necessidade de proteção de direitos que transcendem a dogmática tradicional da individualidade e a necessidade de releitura dos direitos difusos e coletivos à luz da definição de bem comum ou coletivo e da justiça distributiva”.

Silva (2015, p. 81) prossegue explicando que:

O direito do consumidor lida com a distribuição de riscos do mercado de consumo, do mesmo modo que o direito do trabalhador lida com a distribuição de riscos no mercado de produção que são direitos sociais natos e enfrentam questões de identificação dos elementos dos direitos, da formação do bem comum e do seu regime de apropriação. Por conseguinte, o consumidor está para o bem de consumo assim como o trabalhador está para o bem de produção.

Diante disso, verifica-se que, segundo Silva (2015), a noção de tutela jurídica coletiva precisa ser compreendida como uma forma de se defender o consumidor, mas igualmente o trabalhador e o hipossuficiente, de modo que as desigualdades possam ser atenuadas.

Dessa forma, o TAC ou ACDH é o mecanismo através do qual o MP passa a ter poderes para atuar para concretizar normas constitucionais, bem como políticas públicas e direitos humanos, como os direitos socais e coletivos, devido uma ligação entre esses direitos que, segundo o autor, não pode ser ignorada. (SILVA, 2015) 
Rodrigues (2011) explica que o TAC ou ACDH surge no ordenamento jurídico brasileiro para a proteção das relações de consumo em prol de concretizar as diretrizes constitucionais, tendo em vista que, à época, inexistia legislação especifica.

O autor também salienta a relevância da previsão estabelecida no artigo 55 da Lei $n^{\circ}$ 7.244/1984 do Juizado de Pequenas Causas, que dotou de força executiva extrajudicial o acordo firmado perante o Ministério Público, ou seja, atribui eficácia executiva a um recurso de solução de conflitos extrajudicial, contribuindo para a criação do TAC ou ACDH, ainda que se restringisse a tutela de direitos individuais. (RODRIGUES, 2011)

O que se pode observar é que o TAC ou ACDH foi capaz de abranger uma solução extrajudicial de conflito de direitos transindividuais em essência não disponíveis por se demonstrar a iminência ou a verdadeira violação, por meio de uma ação ou omissão, de um direito transindividual. (RODRIGUES, 2011, p. 157)

Segundo Rodrigues (2011), o TAC ou ACDH surge com o manifesto objetivo de fomentar novos mecanismos de tutelar desses direitos, superando aquela velha limitação de que apenas os direitos disponíveis podem ser negociados, bem como proporcionou a possibilidade de ampliação do direito ao acesso à justiça.

O TAC ou ACDH, conforme as lições de Rodrigues (2011), surge como uma resposta a necessidade que se verificava de instrumentos alternativos, que não o judiciário, para tutelar e concretizar de forma mais adequada os direitos transindividuais. É bem verdade que o TAC ou ACDH não substitui as atividades jurisdicionais, mas possui por finalidade lhe completar, em especial nos casos em que se observe que a solução negocial é mais adequada.

Importa salientar que o TAC ou ACDH só poderá atender a essa promessa de ampliação do acesso à justiça se for econômico, curto e justo, caso contrário, as promessas fracassarão. É necessário evitar formalismo excessivo que aumente custos e tempo, bem como não se deve colocar barreiras que limitem seu funcionamento imediato. (RODRIGUES, 2011)

Assim, compreende-se que o TAC ou ACDH é um dos meios de promover o diálogo institucional, de modo que diversos agentes políticos e sociais têm a possibilidade de pactuar, por meio de debates e argumentos, um acordo para atuar em conformidade com as diretrizes constitucionais, bem como com as políticas públicas que tratem de Direitos Humanos, com o benefício de solucionar conflitos em tempo médio, bem menor do que aqueles levados ao Judiciário. (SILVA, 2015) 
Em razão da lentidão desse mecanismo, Rodrigues (2011) aponta que se torna mais difícil a proteção desses direitos, além disso, o TAC ou ACDH é um meio extrajudicial que torna menos onerosa, não somente do aspecto econômico como social, a tutela dos direitos transindividuais do que quando há a necessidade de movimentação do aparato jurisdicional.

Outrossim, é menos custosa até mesmo para os próprios indivíduos envolvidos que estão com seus direitos na eminência de dano ou já lesionados, tendo em vista que não há a exigência de recolhimento de taxas ou custas. (RODRIGUES, 2011)

Acrescenta-se que outro benéfico do TAC ou ACDH é o seu caráter preventivo que torna possível evitar que a lesão ao direito ocorra, pois, o acordo pode ser realizado com próprio responsável pelo fato. Todavia, se o dano já se concretizou, o pacto pode ser feito de forma repressiva para pôr fim a violação e reparar o lesado. (RODRIGUES, 2011)

Sendo um título executivo extrajudicial, o TAC ou ACDH pode ser utilizado para abertura de processos, de maneira que se possa buscar através do Judiciário a concretização dos direitos estabelecidos no acordo, garantindo o acesso à Justiça sem custos, tendo em vista o benefício da gratuidade da justiça, bem como a solução do conflito em massa, de maneira mais pontual, pois a problemática chega ao judiciário com seus contornos já bem delimitados pelo acordo. (SILVA, 2015)

Em razão do exposto, é imprescindível que o objeto do termo seja bem delimitado, ou seja, deve-se fixar de forma adequada a ação ou omissão, a lesão existente ou potencial, para que seja possível, através das obrigações firmadas, defender os direitos em questão. (RODRIGUES, 2011)

Além disso, é indispensável a definição de prazos proporcionais e adequados, bem como o lugar e modo de concretização dos direitos tutelados conforme as particularidades que o caso em questão exija. (SILVA, 2015)

Do mesmo modo, é possível que sejam fixadas sansões nas hipóteses de descumprimento do ajuste ou de violação desses direitos. Pode-se estipular, por exemplo, multa diária como uma medida coercitiva para o cumprimento do acordo. É importante que o valor estipulado leve em consideração a situação econômica do obrigado e a gravidade das consequências resultantes da violação para não ser nem excessiva e nem irrisória, de modo a gerar afetiva pressão psicológica. (RODRIGUES, 2011)

Rodrigues (2011) também chama atenção para a questão de que, por ser um pacto negocial, o TAC ou ACDH garante que os resultados sejam menos onerosos para todos os 
direitos envolvidos e protegidos pelo sistema, de modo que se deve prezar sempre pela proporcionalidade.

O autor também chama a atenção para a importância de a informalidade rodear a técnica extraprocessual. Se garantido um rito pouco padronizado, é possível que as especificidades do caso sejam consideradas para a melhor elaboração do termo. Além disso, permite que o (iminente) transgressor participe ativamente e colabore para a tomada de decisão. Isso reduz as chances de descumprimento que costuma ocorrer quando a obrigação não é assumida espontaneamente, mas por uma ordem de autoridade. (RODRIGUES, 2011)

No que se refere a legitimidade para a celebração do ajustamento, verifica-se a existência de uma legitimidade ativa concorrente entre o Ministério Público, a União, o Estado, o Município, as autarquias, as fundações públicas, as sociedades de economia mista, as empresas públicas e as associações. Outrossim, constata-se que todos possuem legitimidade passiva para ficar obrigado pelo termo. (RODRIGUES, 2011)

É importante ressaltar que o Ministério Público do Trabalho, no exercício de suas funções relacionadas às matérias trabalhistas, poderá firmar termo de ajustamento de conduta para resguardar direitos coletivos e sociais ligados a práticas do labor, bem como para defender o meio ambiente do trabalho. (RODRIGUES, 2011)

No que se tange às formalidades exigidas para o termo, Rodrigues (2011) explica que, em síntese, o termo deve ser escrito, conter justificação sucinta sobre as razões da fixação do termo, pois se trata de um ato do Poder Público sobre direito de uma coletividade, além disso, deve constar o nome das partes subescritoras, o comprometimento expresso de que cumprirá com os termos do ajustamento, as cláusulas que fixam as obrigações estabelecidas de forma inequívoca e o prazo que a obrigação deverá ser cumprida.

Ultrapassada a análise geral do TAC ou ACDH como uma técnica extraprocessual e consensual de concretização de normas constitucionais e Direitos Humanos, em especial os sociais, passa-se a uma análise da utilização deste instrumento como um mecanismo de concretização do trabalho decente dentro do sistema carcerário amazônico.

\section{O TERMO DE AJUSTAMENTO DE CONDUTA COMO INSTRUMENTO DE CONCRETIZAÇÃO DO TRABALHO DECENTE DENTRO DO SISTEMA CARCERÁRIO AMAZÔNICO}


De acordo com Rodrigues (2011), no plano jurídico interno, é a Constituição que estabelece os valores e os princípios que devem orientar a criação e aplicação das normas, de modo a ser o parâmetro para avaliar a conformidade ou não conformidade das leis e atos jurídicos.

No Brasil, a CRFB/88 estabelece, no artigo $1^{\circ}$, os cinco fundamentos do Estado Democrático de Direito. Com isso, no Brasil, só se torna possível justificar o poder do Estado na proporção em que se apresente como uma ferramenta para a concretização desses valores fundamentais. (RODRIGUES, 2011)

Dentre esses fundamentos, é possível verificar que a dignidade da pessoa humana é consagrada no artigo $1^{\circ}$, III CF/88, de modo que todos os indivíduos, sem distinção, são merecedores respeito de forma equitativa, devendo o Estado não somente se abster para não violar esse princípio, mas deve igualmente atuar positivamente para acabar com obstáculos que possa afastar os indivíduos de uma vida digna. (RODRIGUES, 2011)

A dignidade é uma característica preexistente a qualquer direito positivo, devendo ser integralmente garantida a todos os sujeitos, não sendo possível excepcionar nem mesmo ao pior indivíduo condenado, estando prevista, inclusive, na DUDH, que estabelece que todos os indivíduos devem ser considerados iguais em dignidade e direitos. (SARLET, 2006)

Ressalta-se que, de igual modo, a CRFB/88 também consagra como fundamento do Estado Democrático de Direito os valores sociais do trabalho (artigo $1^{\circ}$, IV CRFB/88), passando, com isso, a estabelecer que não é possível que a dignidade seja plenamente usufruída sem o trabalho, razão pela qual o mesmo diploma legal, no artigo $6^{\circ}$, dispõe que o labor é um direito social que deve ser garantido a todos, de modo que o Estado deve atuar por meio de políticas públicas para oportunizar trabalho para todos os indivíduos.

Além disso, verifica-se a impossibilidade de que haja trabalho sem dignidade. Nesse sentido, a CRFB $/ 88$ prescreve, no artigo $7^{\circ}$, um rol de direitos a serem assegurados a todos os trabalhadores urbanos e rurais, sem excluir outros que visem à melhoria de sua condição social, em prol do labor em condições dignas.

Esses direitos de cunho pecuniário têm como fim concretizar o direito ao mínimo existencial, que difere do mínimo vital, tendo em vista que o objetivo não é manter os sujeitos com o mínimo para sobreviver, mas sim para viver com dignidade (SARLET, 2006). 
$\mathrm{Na}$ verdade, o que se constata pelas lições de Brito Filho (2018), é que é imprescindível, para assegurar a dignidade humana e elidir qualquer forma de instrumentalização do trabalhador, garantir o se chama de trabalho decente, entendido como um arcabouço de direitos mínimos necessários a preservação da dignidade do trabalhador.

Parte desses direitos mínimos estão consagrados nos artigos XXII e XXIV, da DUDH, como o direito ao trabalho, a livre escolha do emprego, condições justas de trabalho, proteção contra o desemprego, igualdade no trabalho e de remuneração igual, justa e satisfatória, que seja capaz de garantir ao homem-trabalhador e a sua família condições de vida digna, bem como o direito a limitação da jornada de trabalho, repouso, lazer e férias remuneradas, além do direito de se organizar em sindicatos. (BRITO FILHO, 2018)

Todavia, o autor explica que somente esses direitos não são suficientes para garantir ao homem-trabalhador condições dignas de trabalho, sendo necessário, por isso, recorrer a outros diplomas internacionais, como as "convenções fundamentais" da Organização Internacional do Trabalho (OIT) que prescreve o direito à "liberdade sindical (87 e 98), a proibição do trabalho infantil (29 e 105), a limitação de idade para o trabalho (138 e 182), bem como a proibição de descriminação (100 e 111). ” (BRITO FILHO, 2021, p. 87)

Além disso, segundo o autor, torna-se necessário acrescentar as disposições dos $\operatorname{artigos} 6^{\circ}$ ao $9^{\circ}$ do Pacto Internacional dos Direitos Econômicos, Socais e Culturais para que seja possível verificar os direitos mínimos necessários a garantia do trabalho decente. (BRITO FILHO, 2021)

Diante das previsões normativas elencadas acima, Brito Filho (2018) estabelece que os direitos mínimos necessários as garantias do labor em condições dignas podem ser reunidas em 3 planos: (1) individual, (2) coletivo e (3) da seguridade.

Segundo Brito Filho (2018), plano individual engloba o direito ao trabalho e a liberdade de escolha deste, a "igualdade de oportunidade para e no seu exercício" (p. 52), "o direito de exercer o trabalho em condições que preservem a saúde do trabalhador" (p. 53); o "direito a justa remuneração" (p. 54); “direito a justas condições de trabalho, principalmente limitação da jornada de trabalho e períodos de repouso [...]" (p. 54-55); e a "proibição do trabalho infantil" (p. 55).

No que tange ao plano coletivo, o autor afirma que que engloba o direito à "liberdade sindical" (p. 56) e, sobre o plano da seguridade, o autor explica que engloba a "proteção 
contra o desemprego e outros riscos sociais" (p. 56), entendidos como "aqueles que impedem ou diminuem sua capacidade de subsistência [...]” (p. 56).

Segundo Brito Filho, na hipótese de o homem trabalhador laborar em condições que não assegure todos esses direitos mínimos, estaria sendo anulados Direitos Humanos e, consequentemente, a dignidade do homem trabalhador (BRITO FILHO, 2018).

Ao analisar a situação dos trabalhadores presos, é possível verificar que durante todo o período de cumprimento de pena mentem o seu status de sujeito detentor de dignidade humana. Além disso, os artigos 38 do $\mathrm{CP}$ e $3^{\circ}$ da LEP estabelecem que o encarcerado deve ter conservado todos os direitos não atingidos pela lei, sentença ou perda da liberdade.

Com isso e em vista da noção da dignidade humana, é possível afirmar que o Estado tem do dever de atuar no sistema carcerário para garantir oportunidade de emprego em condições de respeitem à dignidade dos detentos, em especial, pelo fato de que, como a remição é uma forma mais célere de obter a liberdade, obstar o labor decente no cárcere implicaria em retardar o direito constitucional à liberdade e anular os Direitos Humanos e fundamentais dos detentos trabalhadores.

Contudo, conforme já explicado, atualmente, em vista de uma ausência legislativa especifica que tenha por finalidade regulamentar os direitos mínimos a serem assegurados para a concretização do trabalho decente dentro do sistema carcerário brasileiro, bem como que torne o labor carcerário um instrumento efetivo de ressocialização, muitos detentos se encontram ao alvedrio de gestões de mão de obra estaduais que muitas vezes não garante o mínimo necessário em prol da dignidade.

É evidente que a criação do Projeto de Gestão no Amazonas e da Portaria $n^{\circ}$ 465/2020 - GAB/SEAP para tentar regulamentar minimamente alguns dos direitos imprescindíveis para preservação da dignidade do trabalhador apenado é um avanço, mas ainda não garantem uma condição de labor ótima a todos os detentos.

Por exemplo, nenhum dos instrumentos analisados a título de exemplo assegura proteção contra despedida arbitrária ou sem justa causa; seguro-desemprego, em caso de desemprego involuntário; algo que funcione como um Fundo de Garantia por Tempo de Serviço (FGTS) em benefício dos apenados, somente sendo possível o recebimento do percentual de contribuição previdenciária para segurado facultativo.

Outrossim, no que se refere à remuneração, a Portaria do Pará permite que o detento, em algumas atividades, receba bolsas remuneratórias estipuladas em valor inferior ao salário 
mínimo vigente. Todavia, realmente é possível verificar que tanto quando o detento trabalha para conveniadas no Pará, como quando labora no cárcere do Amazonas, o salário mínimo é garantido. Porém, os numerosos e substanciais descontos compensatórios o tornam incapaz de atender as necessidades básicas do preso e de sua família.

Verifica-se ainda que a mão de obra dos apenados sujeitos a regime de cumprimento de pena aberto não foi nem minimamente regulamentado no estado do Amazonas.

Importa destacar também que apenas o Projeto do Amazonas prescreve a necessidade de treinamento do encarcerado para executar suas atividades, bem como do respeito às normas de Segurança e Medicina no Trabalho e do uso dos EPIs e uniforme.

Apenas na Portaria do Pará é possível verificar uma preocupação de inclusão dos detentos maiores de 60 (sessenta) anos e/ou com doença e dos apenados com deficiência $(\mathrm{PcD})$, visto que regulamenta expressamente as atividades laborais desses apenados. Além disso, também é o único instrumento que determina que o Estado deve contratar um seguro acidente de trabalho em benéfico do encarcerado, e, caso não o contrate, caberá aos conveniados promover o seguro.

Por fim, como os sujeitos submetidos a medidas restritivas de liberdade não estão sujeitos ao regime da CLT, alguns benefícios trabalhistas não são garantidos em nenhum dos dois estados, como férias $+1 / 3,13^{\circ}$ salário, FGTS, auxílio-acidente, aviso prévio indenizado ou não, repouso semanal remunerado, feriados e dias santificados e auxilio enfermidade.

É bem verdade que, por estarem sujeitos a uma restrição de liberdade, os apenados que realizam atividades laborais não fazem jus a todos os direitos trabalhistas que são de fato devidos àqueles trabalhadores livres. Todavia, é necessário que seja estabelecido um conjunto de direitos mínimos capaz de assegurar a dignidade humana dos encarcerados, evitando-se, com isso, a superexploração do preso e a precarização do trabalho no sistema carcerário.

Assim, levando em conta que o TAC ou ACDH, segundo Rodrigues (2011), surge exatamente com o objetivo de fomentar novos mecanismos de tutelar direitos transindividuais indisponíveis, superando aquela velha limitação de que apenas os direitos disponíveis podem ser negociados e possibilitando que os direitos sejam concretizados de forma muito mais célere do que pelas vias judiciais, ampliando, com isso, o direito ao acesso à justiça.

Considerando igualmente que, de acordo com Silva (2015), os direitos sociais estão englobados por esses direitos transindividuais e que, ao analisar a gestão de mão de obra no 
Pará e no Amazonas, verifica-se ainda a violação de direitos sociais do trabalhador submetido a uma medida restritiva de liberdade, em decorrência de uma ausência de legislação especifica que defina parâmetros mínimos de direitos a serem garantidos em prol do trabalho decente.

Constata-se que a utilização do TAC ou ACDH entre os agentes políticos e sociais do Pará e Amazonas poderia ser uma técnica adequada de estabelecer, de forma negocial e mais célere, o arcabouço de direitos mínimos necessários ao trabalho decente dentro do sistema carcerário e um prazo bem delimitado para a concretização.

Através desse mecanismo seria possível chegar a um consenso, a partir da análise das particularidades do caso, isto é, das especificidades que diferenciam os trabalhadores presos, de modo a definir os direitos que são devidos àqueles que, apesar de labora em condições que se diferenciam da mão de obra livre, são merecedores de igual respeito e dignidade por parte do Estado, de modo a ser totalmente vedada e abolida a instrumentalização desses sujeitos.

Além disso, essa solução negocial também poderia estabelecer a imprescindibilidade de formação profissional e educação do preso por meio das práticas laborais. Assim, tanto quando o trabalho fosse prestado para a Administração Pública, como para a iniciativa privada, não fosse visado somente o lucro e produtividade, mas que o detento trabalhasse de modo a ser possível, ao final do cumprimento de pena, reintegrar-se ao convívio social vencendo os obstáculos de entrada ao mercado de trabalho e reduzindo a discriminação.

O mesmo poderia ser determinado para os egressos do presidio, que são englobados apenas por uma das gestões. Esses indivíduos também sofrem com efeitos do encarceramento, principalmente com a discriminação no mercado de trabalho. Logo, com o fim de evitar reincidência, o termo poderia restabelecer mecanismo de ressocialização para que esses sujeitos trabalhem e vivam com autonomia e dignidade, evitando, com isso, a reincidência.

Do mesmo modo, frisa-se a importância que o acordo poderia ter ao estipular percentuais razoáveis de descontos compensatórios na remuneração do detento, bem como estabelecer um patamar mínimo de remuneração que, mesmo com os descontos, seja capaz de garantir o direito ao mínimo existencial e vida digna ao encarcerado e a sua família, nos precisos termos do artigo $7^{\circ}, \mathrm{IV}, \mathrm{CRFB} / 88$.

Além disso, o ajustamento poderia dispor, por exemplo, de mecanismos que reduzam os riscos sociais que poderiam impactar as condições de subsistência dos apenados que laboram, tendo em vista que muitos possuem apenas a força de trabalho para viver com dignidade. 
Outrossim, poderia prescrever algo que funcionasse como uma espécie de FGTS, além de mecanismos que evitassem a dispensa arbitrária.

Considerando o caráter preventivo do o TAC ou $\mathrm{ACDH}$, se adequado que reiterasse a necessidade de adoção de todas as medidas para manter o ambiente de trabalho dos detentos seguro e salubre, bem como imprescindíveis para a prevenção de acidentes.

Acrescenta-se a indispensabilidade de que o termo estipule os limites de jornada de trabalho e intervalo, bem como o respeito ao recebimento de horas extraordinárias e adicionais, como noturno, periculosidade e salubridade, quando cabíveis.

Por fim, salienta-se a possibilidade de que o acordo estipule como meta a oferta de vagas de trabalho para apenados em todos os regimes, tendo em vista ser um direito/dever social do preso, se excluir a previsão de outros direitos que poderiam melhor suas condições de trabalho e garantir dignidade humana, considerando as particularidades de cada região.

Assim, e ainda com a possibilidade de estipulação de sansões nas hipóteses de descumprimento do ajuste ou de violação dos Direitos Humanos e fundamentais dos detentos no que se refere à atividade laboral, maior seriam as possibilidades de atuações positivas em prol da dignidade dos sujeitos presos na região Amazônica.

Outrossim, tendo em vista que o TAC ou ACDH é um título executivo extrajudicial, poderia ser utilizado para abertura de processos, na hipótese de não serem respeitados dos termos do acordo, seria possível buscar através do Judiciário a concretização do trabalho decente no cárcere estabelecido no acordo, garantindo o acesso à justiça sem custos e com maior celeridade aos detentos.

Desse modo, supõe-se que o TAC ou ACDH representa uma excelente ferramenta extraprocessual para solucionar o problema de concretização do direito ao trabalho decente a esses sujeitos privados de liberdade, em especial nos estados do Pará e Amazonas, fazendo concretizar os Direitos Humanos e fundamentais.

\section{CONSIDERAÇÕES FINAIS}

À luz do que foi exposto, foi possível verificar que o TAC ou ACDH é uma técnica extraprocessual adequada para concretizar o direito ao trabalho decente aos encarcerados trabalhadores da região Amazônica. 
Para atingir tais resultados, o artigo examinou que, em virtude de uma carência de legislação especifica que regulamente os direitos mínimos a serem garantidos aos encarcerados em prol da preservação da dignidade humana no labor, cada estado fica responsável por regular e administrar a exploração da mão de obra dos encarcerados.

Com isso, na região Amazônica, muitos detentos estão à mercê de instrumentos de administração do trabalho que são incapazes de garantir condições ótimas de labor para todos por meio de um arcabouço mínimo de direitos em prol do trabalho em condições que lhes preserve a dignidade, ou seja, que garanta o direito ao trabalho decente.

Por exemplo, no estado do Pará e Amazonas, dois dos estados que abrigam a maior massa carcerária da região, verificou-se a existência da Portaria n 465/2020 GAB/SEAP/PA e o Projeto de Gestão de mão de obra do Amazonas. Diante disso, constatou-se que ambos os instrumentos representam um progresso, pois asseguram alguns dos direitos mínimos necessários ao labor em condições dignas, mas ainda são deficientes.

Isto posto, tendo em vista que a dignidade é um dos fundamentos do Estado Democrático de Direito (artigo $1^{\circ}$, III, CRFB/88), assim como os valores sociais do trabalho (artigo $1^{\circ}, \mathrm{IV}, \mathrm{CRFB} / 88$ ), não há como haver dignidade sem trabalho, bem como não se poderá permitir o labor sem dignidade, devendo o Estado atuar positivamente para garantir oportunidade de trabalho em moldes dignos, evitando a instrumentalização do trabalhador.

Dentre os instrumentos a disposição do Estado para concretização e prevenção de lesão de direitos, constatou-se que o TAC ou ACDH é um mecanismo extrajudicial econômico de concretização de normas constitucionais e Direitos Humanos, em especial os sociais e coletivos, que objetiva, por exemplo, a proteção do trabalhador. (SILVA, 2015)

Além disso, é um acordo que possui como benefícios possibilitar a negociação de direitos indisponíveis, facilitar o cumprimento e adesão às cláusulas do acordo, ser mais célere do que os meios judicias, além de ser mais econômico financeira e socialmente. (RODRIGUES, 2011 )

Outrossim, analisou-se que, no caso de descumprimento, sendo um titulo executivo extrajudicial, o TAC ou ACDH pode ser usado para abertura de processos para buscar por vias judicias a prevenção, concretização ou reparação do direito com o beneficio da justiça gratuita, ampliando, por todo o exposto, o acesso à justiça. (SILVA, 2015)

A pesquisa, em consideração a isso, explicou que a mão de obra presa se diferencia do trabalhador livre, tornando evidente que não faz jus a todos os direitos previstos na CLT, 
todavia mantém seu direito a dignidade, logo é merecedora de um conjunto de direitos mínimos em prol do trabalho decente, evitando precarização e superexploração no cárcere.

Em razão disso, frisou-se que, através desse do TAC ou ACDH, seria possível analisar as especificidades do caso e fixar cláusulas que definissem e concretizasse esse arcabouço mínimo de direito. Além disso, na hipótese de violação do ajuste e dos direitos, seria possível fixar sansões, estimulando a atuações positivas dos agentes públicos em prol da dignidade dos sujeitos presos que trabalham na região Amazônica.

Salientou-se também que, como o acordo é um título executivo extrajudicial, seria cabível usa-lo na abertura de processos, na hipótese de desrespeito aos termos ou direitos tutelados, buscando, assim, por vias judiciais de forma gratuita a concretização do trabalho decente no cárcere, garantindo o acesso à justiça sem custos e com maior celeridade aos detentos.

Desse modo, concluiu-se que o TAC ou ACDH representa uma excelente ferramenta extraprocessual para solucionar o problema decorrente da carência legislativa que vise fixar direitos mínimos em prol do respeito à dignidade humana do preso no campo sócio laborativo, definição de prazos, lugar e modo de concretização do direito ao trabalho decente aos sujeitos privados de liberdade na região amazônica.

\section{REFERÊNCIAS}

BRASIL, Constituição Brasileira (1988). Constituição da República Federativa do Brasil: promulgada em 5 de outubro de 1988. Disponível em:

http://www.planalto.gov.br/ccivil_03/Constituicao/Constituicao.htm. Acesso em 05/07/2020

BRASIL. Decreto-Lei $\mathbf{n}^{\mathbf{0}}$ 5.452, de $1^{\circ}$ de maio de 1943. Disponível em:

http://www.planalto.gov.br/ccivil_03/decreto-lei/del5452.htm. Acesso em: 18 jul. 21. 2010.

BRASIL. Decreto-Lei no 2.848, de 7 de dezembro de 1940. Disponível em:

http://www.planalto.gov.br/ccivil_03/decreto-lei/del2848compilado.htm. Acesso em: 2 nov. 2020.

BRASIL. Lei no 7.210, de 11 de julho de 1984. Disponível em:

http://www.planalto.gov.br/ccivil_03/leis/17210.htm. Acesso em: 1 nov. 2020.

BRITO FILHO, José Cláudio Monteiro de. Justiça: temas de liberalismo igualitário, uma homenagem aos 50 anos de uma teoria da justiça de John Rawls. Brasília-DF: Editora Venturoli, 2021 
BRITO FILHO, José Claudio Monteiro. Trabalho Decente: Análise Jurídica da Exploração do Trabalho - Trabalho Escravo e outras formas de Trabalho Indigno. $5^{\text {a }}$ Ed. São Paulo: LTr, 2018.

GRECO, Rogério. Curso de Direito Penal: Parte Geral. 17 ed. Rio de Janeiro: Impetus, 2015 .

JULIÃO, Elionaldo Fernandes. Ressocialização através da educação e do trabalho no Sistema Penitenciário Brasileiro. Tese (Doutorado). Universidade do Estado do Rio de Janeiro. Instituto de Filosofia e Ciências Humanas, 2009, 440p.

ORGANIZAÇÃO DAS NAÇÕES UNIDAS. Declaração Universal dos Direitos Humanos, 1948. Disponível em: https://www.unicef.org/brazil/declaracao-universal-dos-direitoshumanos. Acesso em: 12 dez. 2020.

RODRIGUES, Geisa de Assis. Ação civil pública e termo de ajustamento de conduta: teoria e prática. $3^{\circ}$ ed. Rio de Janeiro: Forense, 2011.

SARLET, Ingo Wolfgang. Dignidade da Pessoa Humana e Direitos Fundamentais na Constituição de 1988. 10 ${ }^{\text {a }}$ Ed. Porto Alegre: Livraria do Advogado Editora, 2015.

Secretária de Estado de Administração penitenciaria. Projeto trabalhando a liberdade: criação de grupo de trabalhadores para utilização de mão de obra prisional. Manaus. 2019

Secretária de Estado de Administração penitenciaria. Apresentação trabalho do preso. Manaus. 2019

SILVA, Sandoval Alves da. A Tutela Coletiva Extraprocessual: O Diálogo Institucional como Instrumento de Atuação do Ministério Público para a Concretização dos Direitos Sociais. 2015. Tese (Doutorado em Direito) - Faculdade de Direito, Universidade Federal do Estado do Pará, Belém, 2015. Disponível em:

http://repositorio.ufpa.br/jspui/bitstream/2011/7501/1/Tese_TutelaColetivaExtraprocessual.pd f. Acesso em: 23 nov. 2020. 